\title{
Sleep Disturbance and Risk of Active Disease in Patients with Crohn's Disease and Ulcerative Colitis
}

\author{
Ashwin N Ananthakrishnan ${ }^{1,2}$, Millie D Long ${ }^{3}$, Christopher F Martin ${ }^{3}$, Robert S Sandler ${ }^{3}$, \\ and Michael D Kappelman ${ }^{4}$ \\ ${ }^{1}$ Division of Gastroenterology, Massachusetts General Hospital, Boston, MA \\ ${ }^{2}$ Harvard Medical School, Boston, MA \\ ${ }^{3}$ Division of Gastroenterology and Hepatology, Department of Medicine, University of North \\ Carolina, Chapel Hill, NC \\ ${ }^{4}$ Division of Gastroenterology, Department of Pediatrics, University of North Carolina, Chapel Hill, \\ NC
}

\begin{abstract}
Background \& Aims-Impairment of sleep quality is common in patients with inflammatory bowel diseases (IBD; Crohn's disease [CD], ulcerative colitis [UC]), even during clinical remission. Sleep impairment can activate inflammatory pathways. Few prospective studies have examined the role of sleep disturbance on risk of relapse in IBD.
\end{abstract}

\begin{abstract}
Methods-We analyzed data from 3173 patients with IBD (1798 in clinical remission at baseline) participating in the Crohn's and Colitis Foundation of America Partners study, a longitudinal, internet-based cohort. Sleep disturbance was measured using a subset of questions from the Patient Reported Outcomes Measurement Information Systems sleep disturbance questionnaire. Disease activity was assessed using the short Crohn's disease activity index and simple clinical colitis activity index for $\mathrm{CD}$ and $\mathrm{UC}$ respectively. Logistic regression was used to identify predictors of sleep quality and examine the effect of sleep quality at baseline among patients in remission on risk of active disease at 6 months.
\end{abstract}

\begin{abstract}
Results-Disease activity, depression, female gender, smoking, and use of corticosteroids or narcotics were associated with sleep disturbance at enrollment. Among 1291 patients whose CD was in remission at baseline, those with impaired sleep had 2-fold increase in risk of active disease at 6 months (adjusted odds ratio [OR], 2.00; 95\% confidence interval [CI], 1.45-2.76); no effect was observed in patients with UC (OR 1.14; 95\% CI $0.75-1.74)$. These findings persisted in a number of sensitivity analyses.
\end{abstract}

\footnotetext{
(C) 2013 The American Gastroenterological Association. Published by Elsevier Inc. All rights reserved.

Corresponding author: Ashwin N Ananthakrishnan, MD, MPH, Massachusetts General Hospital Crohn's and Colitis Center, 165 Cambridge Street, $9^{\text {th }}$ Floor, Boston, MA 02114, Phone: 617-724-9953, Fax: 617-726-3080, aananthakrishnan@ partners.org.

Author contributions: Ananthakrishnan - study concept and design, analysis and interpretation, drafting of the manuscript; Long study design, data collection, interpretation of results, final approval of manuscript; Martin - study design, data collection, analysis and interpretation of results, final approval of manuscript; Sandler - data collection, interpretation of results, final approval of manuscript; Kappelman - study design, data collection, interpretation of results, final approval of manuscript

Conflicts of Interest: None

Publisher's Disclaimer: This is a PDF file of an unedited manuscript that has been accepted for publication. As a service to our customers we are providing this early version of the manuscript. The manuscript will undergo copyediting, typesetting, and review of the resulting proof before it is published in its final citable form. Please note that during the production process errors may be discovered which could affect the content, and all legal disclaimers that apply to the journal pertain.
} 
Conclusion-Sleep disturbance was associated with an increased risk of disease flares in CD but not UC. These findings indicate that the evaluation and treatment of sleep disturbance in patients with CD might improve outcomes.

\section{Keywords}

intestinal inflammation; environment; PROMIS; prospective cohort study

\section{INTRODUCTION}

Inflammatory bowel diseases (IBD; Crohn's disease (CD), ulcerative colitis (UC)) are chronic immunologically mediated diseases of the intestine that often have their onset during young adulthood and are characterized by a chronic relapsing and remitting course $^{1,2}$. They are associated with considerable morbidity, need for surgery and hospitalizations, and impairment of health-related quality of life ${ }^{3,4}$. However, despite our understanding that external environment, behavior, and lifestyle play an important role in the pathogenesis and natural history of $\mathrm{CD}$ and $\mathrm{UC}^{5-8}$, such factors remain poorly studied. In particular, there has been little study of behavioral factors other than smoking that might influence disease activity, but that could also be modifiable and reduce the risk of active disease.

Sleep disturbances are common in the population and associated with a spectrum of adverse outcomes including being a risk factor for obesity, weight gain, metabolic syndrome, depression, and mortality ${ }^{9-11}$. Prior studies support the biological plausibility that disturbed sleep may be a modifiable behavioral risk factor for disease relapse in IBD patients ${ }^{12-17}$. Patients with IBD, even during period of inactivity, have a higher prevalence of impaired sleep quality than healthy controls ${ }^{14}$. In animal models, acute or chronic sleep deprivation increases susceptibility to dextran sodium sulfate (DSS)-induced colitis, a widely used mouse model of $\mathrm{IBD}^{18}$. Key cytokines involved in chronic inflammation including tumor necrosis factor-a (TNF), interleukin-1 (IL-1), and interleukin-6 (IL-6) affect sleep ${ }^{17}$. In human studies of juvenile idiopathic arthritis, administration of anti-TNF biologic therapy improves sleep quality in addition to the achieving disease remission ${ }^{19}$. There have been no prior studies examining the association between sleep quality in remission and risk of subsequent disease flare in patients with established CD or UC.

In the context of a large prospective IBD cohort, we performed this study with the following aims: (1) to identify predictors of sleep quality among patients with CD and UC; and (2) to examine if sleep quality during remission is associated with subsequent risk of symptomatic flares in patients with CD and UC.

\section{METHODS}

\section{Study Cohort and variables}

The data source for this study was the Crohn's and Colitis Foundation of America (CCFA) Partners IBD cohort. The creation of this cohort has been described in detail in previous publications $^{20,21}$. In brief, CCFA Partners is a longitudinal internet-based cohort of patients with IBD. Participants with a self-reported diagnosis of UC, CD, or indeterminate colitis (IC) who were older than age 18 years were invited to participate in the study through the CCFA email roster, social media, and at educational events ${ }^{21}$. All participants completed a baseline survey comprising demographics and information about their IBD. Optional modules on various patient-reported outcomes were included with the baseline survey. They were then invited to complete a follow-up questionnaire at 6 months after enrollment, 
ascertaining disease activity as well as any changes in their treatment and repeated measures of patient-reported outcomes.

\section{Assessment of sleep disturbance}

Our main predictor variable of interest was sleep disturbance. This was ascertained using a subset of questions from the National Institutes of Health Patient Reported Outcomes Measurement Information Systems (PROMIS) sleep disturbance questionnaire ${ }^{22,23}$. The PROMIS sleep disturbance questionnaire was carefully developed within the PROMIS domain framework by first creating an initial pool of items identified from 535 candidate citations. Focus-groups were then held among those with sleep disorders and normal sleepers, and the question bank pilot tested in a national sample of 300 participants and a clinical sample. Subsequent psychometric testing using classic test theory and item response theory analyses were used to arrive at the final questionnaire which demonstrated excellent measurement properties. The short form of the PROMIS questionnaire has comparable performance to the widely used Pittsburgh Sleep Quality Index (PSQI) and greater ability to discriminate between different levels of sleep disturbance ${ }^{23,24}$. Furthermore, the response burden to the PROMIS sleep questions is lower than for the 10-item PSQI, does not require participation of a sleeping partner, and is consistent with ascertainment of other patientreported outcome measures in this cohort. In addition, each PROMIS question from the 29item bank is designed as a stand alone question with the same final score irrespective of the number of questions completed ${ }^{25}$.

For this study, patients were administered four questions that examined sleep quality. Respondents were asked if over the past 7 days, (1) their sleep quality was good, (ii) their sleep was refreshing, (iii) they had a problem with their sleep, or (iv) they had difficulty falling asleep. Responses were scored on a 5-point Likert scale. The sum of the responses was normalized to a T-score with mean of 50 and a standard deviation (SD) of 10 (www.nihpromis.org). Thus, a T-score of 50 refers to the median sleep quality with higher scores indicating a greater degree of sleep disturbance. Patients with a sleep T-score $>50$ were considered as having disturbed sleep while T-scores $<50$ were considered normal. In sensitivity analyses, we defined disturbed sleep as requiring a T-score $>60$, and as a continuous variable. To validate our use of the PROMIS questions, a subset of patients were also administered the PSQI. Correlation between the two questionnaires was examined using the Pearson correlation co-efficient.

\section{Other Variables}

Self-reported disease location and behavior in CD and extent of involvement in UC was classified according to the Montreal classification ${ }^{26}$. Information was obtained about IBDrelated hospitalization or surgery, as well as medications for treatment of IBD including 5aminosalicylates (oral), corticosteroids (oral), immunomodulators, and biologic therapies (infliximab, adalimumab, certolizumab pegol, and natalizumab). Disease activity was assessed using validated measures - the short Crohn's disease activity index (SCDAI) for $\mathrm{CD}^{27}$ and the simple clinical colitis activity index (SCCAI) for $\mathrm{UC}^{28}$. A SCDAI $<150$ or an SCCAI $\leq 2$ indicated clinical remission for $\mathrm{CD}$ and $\mathrm{UC}$ respectively with values above this threshold indicating active disease ${ }^{21}$. Baseline depressive symptoms were ascertained using a PROMIS depression T-score scored similar to the sleep T-score. Medication adherence was assessed using the Morisky Medication Adherence Scale (MMAS) ${ }^{29}$. Smoking status was stratified as never, past, and current smoking at the time of baseline questionnaire with very few ( $<10$ patients) describing a change in their smoking status at 6 months. 


\section{Outcomes}

Our primary outcome was presence of active disease at 6 months. This was defined as SCDAI > 150 for CD or SCCAI > 2 for UC on the 6-month follow-up questionnaire. As a secondary outcome, we assessed an expanded definition of disease flare which included either a disease activity index above the threshold above, or initiation of a new IBD medication, requirement for an IBD-related surgery or hospitalization between the baseline and follow-up visit. In the validation study, patient and physician reports matched $98 \%$ of the time for ever having bowel surgery, and current pouch or ostomy status. In a sensitivity analysis, we used an alternate definition of active disease that included an SCDAI $>150$ and a 100-point increase in SCDAI from baseline for CD and an SCCAI > 5 for UC.

\section{Statistical Analysis}

All analysis was performed using Stata 11.0 (StataCorp, College Station, TX). Continuous variables were summarized using means and standard deviations and compared using the ttest. Categorical variables, expressed as proportions, were compared using the chi-square test. Univariate and multivariable logistic regression models were constructed to identify predictors of disturbed sleep at cohort entry. This analysis included the entire cohort of 3,173 patients. Next, among participants who were in clinical remission at baseline $(\mathrm{n}=1,798)$, we evaluated the association between sleep disturbance during remission and risk of disease flare. Variables significant in the univariate analyses at $\mathrm{p}$-value $<0.10$ were included in the final multivariable regression models where a p-value $<0.05$ indicated independent statistical significance. The study was approved by the Institutional Review Board (IRB) of Massachusetts General Hospital. The CCFA Partners cohort study was approved by the IRB of University of North Carolina, Chapel Hill.

\section{RESULTS}

\section{Study Cohort}

A total of 4,366 individuals who had both a baseline and a 6-month follow-up survey were eligible for inclusion in our study. The median interval between completion of the baseline and follow-up survey was 7 months (interquartile range (IQR) 6.5 - 7.8 months). After excluding patients with a stoma or pouch (as standard symptom-based measures of disease activity are not applicable to these patients), indeterminate colitis, a change in their IBD diagnosis during the follow-up period, and those with missing data on sleep disturbance or disease activity scores, we arrived at the final cohort of 3,173 patients (Figure 1). A total of 1,798 patients (507 UC, $1291 \mathrm{CD}$ ) were in clinical remission at baseline. Patients excluded from the study were similar to the final cohort in age and gender, were slightly more likely to have UC, and had a lower frequency of prior hospitalization or surgery.

\section{Validation of assessment of sleep disturbance}

A total of 773 patients completing the 6-month follow-up questionnaire completed both the PSQI and the PROMIS sleep T. Overall, there was a strong correlation between the two scores (correlation co-efficient $0.80, \mathrm{p}<0.0001$ ). The correlation remained good for patients with active disease or in remission, and by IBD type. The mean PSQI for those without or with sleep impairment by the PROMIS sleep-T scores was 4 and 9 respectively $(\mathrm{p}<0.0001)$. Four-fifths $(82 \%)$ of patients with sleep-T scores above the median and $98 \%$ of those with sleep-T scores above 60 had a PSQI $>5$.

\section{Predictors of sleep disturbance at baseline}

Nearly two-thirds of patients (60\%) in the study had sleep disturbance at baseline. Such patients were more likely to be female, have $\mathrm{CD}$, or have a history of smoking $(\mathrm{p}<0.05$ for 
all) (Table 1). They were also more likely to be currently using systemic corticosteroids, narcotics, or anti-TNF biologic therapies, and were more likely to have ever required an IBD-related hospitalization or surgery. Over half the patients with sleep disturbance had active disease (55\%) compared to a quarter of those with no sleep disturbance $(26 \%)(\mathrm{p}<$ 0.001 ). Conversely, $48 \%$ of those in remission at baseline had sleep T-scores $>50$ compared to $76 \%$ of those with active disease ( $\mathrm{p}<0.001)$. On multivariable analysis, the strongest predictors of disturbed sleep were depressive symptoms (Odds ratio (OR) 2.75, 95\% confidence interval (CI) $2.34-3.23$ ) and the presence of active disease (OR 2.61, 95\% CI $2.19-3.11$ ), while female gender, diagnosis of $\mathrm{CD}$, and both past and current smoking conferred modest risks (Table 2). Current use of corticosteroids and narcotics, but not antiTNF biologics or immunomodulators also independently increased risk of sleep disturbance.

\section{Sleep disturbance and risk of disease flare in Crohn's disease}

Half of the 1,291 patients with CD in remission at baseline had disturbed sleep ( $\mathrm{n}=651$, $50 \%$ ). Participants with sleep disturbance while in clinical remission were more likely to be women, have $\mathrm{CD}$ or have a history of smoking. Neither corticosteroids nor narcotic use were associated with disturbed sleep in this cohort likely owing to their low frequency of use among those in remission (Table 3). Among those with disturbed sleep, 22\% of those in remission had active disease at month 6 compared to $12 \%$ of those without disturbed sleep (OR 1.96, 95\% CI 1.45 - 2.65). On multivariable analysis, presence of sleep disturbance was associated with twofold increase in risk of disease flare at 6 months (OR 2.00, 95\% CI $1.45-2.76$ ) (Table 4). Using the expanded definition of disease flare incorporating either active symptoms or initiation of new therapies, we found a similar effect of sleep disturbance on disease flare (OR 1.64, 95\% CI 1.27 - 2.11). Defining disease flare as requiring both a SCDAI > 150 and a 100-point increase in the score from baseline also yielded a similar effect size (OR 1.70, 95\% CI $1.09-2.65$ ). To explore the possibility of subclinical symptoms at baseline below our remission threshold influencing sleep status and likelihood of flare, in a sensitivity analysis we defined remission as SCDAI $\leq 200$, and active disease on follow-up as values above this threshold. The association with sleep impairment and subsequent active disease was further strengthened on this analysis (OR $1.95,95 \%$ CI $1.37-2.79$ ). Participants who had no impaired sleep at baseline but sleep impairment on follow-up and follow-up surveys were significantly more likely to have active disease at the follow-up (OR 2.37, 95\% I CI 1.46 - 3.86) than those whose sleep remained unimpaired. Adjusting for baseline body mass index did not influence our results. Similar results were found after adjusting for medication adherence using the MMAS (data available on 832 patients) (OR 1.63, 95\% CI $1.10-2.42$ ) or depressive symptoms (data available on 1206 patients) (OR 1.77, 95\% CI $1.27-2.45$ ). On a continuous scale, each 10 point (1 standard deviation) increase in the PROMIS sleep T-score was associated with a $50 \%$ increase in risk of disease flare (OR 1.46, 95\% CI 1.19 - 1.79) (Table 5). Patients with the greatest disturbance in sleep quality (PROMIS T-score > 60) had an OR of 2.21 (95\% CI $1.30-3.77$ ) compared to those with T-scores of 50 or less (Table 5). We did not find a statistically significant interaction by age, gender, disease phenotype, depressive symptoms, or medication adherence in susceptibility to the effect of sleep disturbance $(\mathrm{p}>0.05$ for all interactions).

\section{Sleep disturbance and risk of disease flare in ulcerative colitis}

In contrast to its effect on $\mathrm{CD}$, we observed no effect between sleep disturbance at baseline and risk of disease flare in UC using either our primary (OR 1.14, 95\% CI $0.75-1.74$ ) or expanded definitions of disease flare (OR 1.14, 95\% CI $0.75-1.74$ ) (Table 4). 


\section{DISCUSSION}

Sleep impairment is common in chronic inflammatory diseases ${ }^{13-17,30-37}$. Biologic mechanisms support a potential role for sleep impairment in disease relapse in IBD ${ }^{15-17}$; nevertheless there are no published studies examining this hypothesis. Using a large IBD cohort, we demonstrate that $\mathrm{CD}$ patients who have impaired sleep quality while in clinical remission have a greater risk of disease flare. We did not identify this effect in UC.

There has been limited research on sleep disturbances in patients with IBD. Ranjbaran et al. administered the PSQI to 205 patients with IBD, IBS or healthy controls and found that patients with IBD, despite being in remission, had significantly prolonged sleep latency, sleep fragmentation, decreased daytime energy and poor overall sleep quality compared to healthy controls ${ }^{15}$. Sleep quality was associated with lower health-related quality of life $(\mathrm{HRQOL})^{15}$. However the assessment of sleep quality and HRQoL was cross-sectional (i.e. at the same time point). A larger study of 318 patients with CD and UC demonstrated that $77 \%$ of those with active and $49 \%$ of those with inactive disease experienced poor sleep measured using the PSQI ${ }^{33}$. This is nearly identical to our proportion of $76 \%$ and $48 \%$ of those with active disease or in remission using the PROMIS sleep questions.

Impairment of sleep in patients with IBD is likely multifactorial. During periods of active disease, the need for nocturnal bowel movements as well as persistence of symptoms such as abdominal pain can result in sleep disturbance. Second, medications frequently used in the setting of active disease such as corticosteroids or narcotics may result in impaired sleep. Third, associated psychiatric co-morbidities including depression and anxiety more common in IBD patients ${ }^{38}$ also influence sleep quality. However, we found that nearly half the patients in clinical remission also had impaired sleep quality. One hypothesis for this occurrence is the presence of subclinical inflammation in such patients. Injection of IL-1 or TNF- $a$ in animal models suppresses rapid-eye movement (REM) sleep and alters sleep patterns ${ }^{39}$. Administration of IL-6 increases non-rapid eye movement sleep (NREM) and reduces slow wave sleep during the first half of the sleep cycle ${ }^{40}$. Thus, elevated circulating cytokines in patients in clinical remission could contribute to the sleep disturbances.

A key and novel finding of our study is that CD patients who had disturbed sleep even while in clinical remission had nearly two-fold increase in likelihood of disease flare at 6 months compared to those with unimpaired sleep. Considerable laboratory evidence supports the biologic plausibility of such an association. Sleep deprivation in humans is associated with an increase in IL-6 and TNF soluble receptors ${ }^{16,17,37}$. In an elegant study, Tang et al. examined the effect of sleep deprivation on susceptibility to DSS-induced colitis ${ }^{18}$. Three groups of twelve mice each were subjected to acute sleep deprivation (24 hours), chronic intermittent sleep deprivation (10 days), and no deprivation. Both the acute and chronically sleep deprived mice displayed increased susceptibility to DSS colitis and exacerbation of colon inflammation ${ }^{18}$. Additionally, TNF-a can influence expression of clock genes which are involved in regulating intestinal permeability ${ }^{17,41}$. Finally, sleep disturbance is associated with activation of natural killer cells and monocytes ${ }^{17,37,41}$. There is less direct evidence for why we observed an effect on CD but not UC. This is unlikely to be related to statistical power given similar number of patients with CD or UC in our study, similar rates of active disease, and widely used measures of disease activity. Thus, it is possible that sleep quality as an environmental variable truly does not impact the course of ulcerative colitis. While the vast number of genetic risk loci for $\mathrm{CD}$ and $\mathrm{UC}$ are shared, distinct dominant pathways exist in the pathogenesis of each disease ${ }^{7}$. Our findings add to the literature demonstrating differential effect of various environmental factors on $\mathrm{CD}$ and $\mathrm{UC}-$ classically smoking and appendectomy. The mechanisms for this divergence in effect for any of the parameters described remained yet undefined. Identifying such divergence in 
effects provides strong impetus to understanding the mechanisms how the environment may influence different components of the immune system, and may help further our understanding of the pathogenesis of these diseases.

There are several implications to our findings. The association between sleep impairment and disease relapse suggests a need to incorporate assessment of sleep quality more routinely in our care of patients with IBD. Identification of sleep disturbances could potentially yield a modifiable risk factor to reduce the likelihood of subsequent disease relapse. There is need for research on the effectiveness of interventions to improve sleep quality. Also, given the identified association between corticosteroid and narcotic use and sleep quality, it is important for the treating physician to recognize these iatrogenic causes of sleep impairment, potentially modify treatment regimens, or institute interventions to address these treatment-related adverse effects. As well, identification of an association between depressive symptoms and sleep quality suggests the need to also continue to incorporate routine screening for psychiatric co-morbidity in the management of patients with IBD.

We acknowledge several limitations to our study. First, the CCFA Partners cohort is a volunteer sample of patients. It is possible that the IBD patients enrolled in CCFA Partners may differ from a population-based IBD cohort. Nevertheless, the prevalence of sleep disturbance stratified by disease activity at baseline in our cohort is similar to that identified in the Manitoba population-based IBD cohort, suggesting our results may be generalizable to the larger IBD population. Second, diagnosis of IBD was by self-report. However, according to preliminary results from a validation study in which the treating physicians of randomly selected members of the cohort were mailed a 10-item questionnaire to confirm IBD type and diagnosis, IBD status was confirmed in $96 \%$ of the cohort, with matching IBD type confirmed $94 \%$ of the time (data not shown). Third, information on disease phenotype, treatment, and disease activity was by self-report. The bias introduced due to this is unlikely to be differential by sleep impairment. The use of symptom-based disease activity scores is also subject to limitations including influence by superimposed irritable bowel syndrome. However, we attempted to increase the robustness of our results by demonstrating consistency of effect using an alternate definition that relied not just on symptom-based indices but also more objective measures including initiation of new IBD treatments, surgery or hospitalizations. We also did not have information on whether patients were on sleep aids at the time of assessment. However, this misclassification is also likely to bias towards the null, making our results a conservative estimate. Both sleep quality and disease activity was assessed for the 1 week period prior to completion of the questionnaire, allowing for these to be more representative measures that 24-hour recall. As in all observational studies, the possibility of unmeasured confounders exists. We attempted to adjust for most of the known important environmental factors, but were not able to fully capture all possibilities including use of over the counter medications. Finally, we examined outcomes up to 6 months after assessment of sleep quality. It is important to continue studies of environmental, behavioral, and lifestyle factors beyond this time frame to identify the long-term impact of such variables.

In conclusion, we identified sleep impairment during remission to be a risk factor for disease flares in CD in a large IBD cohort. Continued research is needed to further understand the mechanisms behind such an association. Furthermore, our findings suggest that sleep quality could be a modifiable factor in reducing risk of disease relapses in IBD. There is need for further research on the potential benefits of routine assessment of sleep quality as well as intervention-based studies to improve sleep quality in patients with $\mathrm{CD}$ which may ultimately impact patient outcomes. 


\section{Acknowledgments}

Source of funding: Ananthakrishnan is supported in part by a grant from the National Institutes of Health (K23 DK097142). CCFA Partners cohort is supported by grants from the Crohn's and Colitis Foundation of America and the National Institutes of Health (P30 DK34987)

\section{References}

1. Abraham C, Cho JH. Inflammatory bowel disease. N Engl J Med. 2009; 361:2066-78. [PubMed: 19923578]

2. Loftus EV Jr, Sandborn WJ. Epidemiology of inflammatory bowel disease. Gastroenterol Clin North Am. 2002; 31:1-20. [PubMed: 12122726]

3. Bernstein CN, Loftus EV Jr, Ng SC, Lakatos PL, Moum B. Hospitalisations and surgery in Crohn's disease. Gut. 2012; 61:622-9. [PubMed: 22267595]

4. Hommes D, Colombel JF, Emery P, Greco M, Sandborn WJ. Changing Crohn's disease management: need for new goals and indices to prevent disability and improve quality of life. $\mathrm{J}$ Crohns Colitis. 2012; 6 (Suppl 2):S224-34. [PubMed: 22463929]

5. Cosnes J, Gower-Rousseau C, Seksik P, Cortot A. Epidemiology and natural history of inflammatory bowel diseases. Gastroenterology. 2011; 140:1785-94. [PubMed: 21530745]

6. Danese S, Fiocchi C. Etiopathogenesis of inflammatory bowel diseases. World J Gastroenterol. 2006; 12:4807-12. [PubMed: 16937461]

7. Khor B, Gardet A, Xavier RJ. Genetics and pathogenesis of inflammatory bowel disease. Nature. 2011; 474:307-17. [PubMed: 21677747]

8. Lakatos PL. Environmental factors affecting inflammatory bowel disease: have we made progress? Dig Dis. 2009; 27:215-25. [PubMed: 19786744]

9. Baglioni C, Battagliese G, Feige B, Spiegelhalder K, Nissen C, Voderholzer U, Lombardo C, Riemann D. Insomnia as a predictor of depression: a meta-analytic evaluation of longitudinal epidemiological studies. J Affect Disord. 2011; 135:10-9. [PubMed: 21300408]

10. Gangwisch JE, Heymsfield SB, Boden-Albala B, Buijs RM, Kreier F, Opler MG, Pickering TG, Rundle AG, Zammit GK, Malaspina D. Sleep duration associated with mortality in elderly, but not middle-aged, adults in a large US sample. Sleep. 2008; 31:1087-96. [PubMed: 18714780]

11. Hall MH, Muldoon MF, Jennings JR, Buysse DJ, Flory JD, Manuck SB. Self-reported sleep duration is associated with the metabolic syndrome in midlife adults. Sleep. 2008; 31:635-43. [PubMed: 18517034]

12. Abad VC, Sarinas PS, Guilleminault C. Sleep and rheumatologic disorders. Sleep Med Rev. 2008; 12:211-28. [PubMed: 18486034]

13. Graff LA, Walker JR, Russell AS, Bissonnette R, Bernstein CN. Fatigue and quality of sleep in patients with immune-mediated inflammatory disease. J Rheumatol Suppl. 2011; 88:36-42. [PubMed: 22045977]

14. Keefer L, Stepanski EJ, Ranjbaran Z, Benson LM, Keshavarzian A. An initial report of sleep disturbance in inactive inflammatory bowel disease. J Clin Sleep Med. 2006; 2:409-16. [PubMed: 17557469]

15. Ranjbaran Z, Keefer L, Farhadi A, Stepanski E, Sedghi S, Keshavarzian A. Impact of sleep disturbances in inflammatory bowel disease. J Gastroenterol Hepatol. 2007; 22:1748-53. [PubMed: 17914945]

16. Ranjbaran Z, Keefer L, Stepanski E, Farhadi A, Keshavarzian A. The relevance of sleep abnormalities to chronic inflammatory conditions. Inflamm Res. 2007; 56:51-7. [PubMed: 17431741]

17. Swanson GR, Burgess HJ, Keshavarzian A. Sleep disturbances and inflammatory bowel disease: a potential trigger for disease flare? Expert Rev Clin Immunol. 2011; 7:29-36. [PubMed: 21162647]

18. Tang Y, Preuss F, Turek FW, Jakate S, Keshavarzian A. Sleep deprivation worsens inflammation and delays recovery in a mouse model of colitis. Sleep Med. 2009; 10:597-603. [PubMed: 19403332] 
19. Ruperto N, Lovell DJ, Li T, Sztajnbok F, Goldenstein-Schainberg C, Scheinberg M, Penades IC, Fischbach M, Alcala JO, Hashkes PJ, Hom C, Jung L, Lepore L, Oliveira S, Wallace C, Alessio M, Quartier P, Cortis E, Eberhard A, Simonini G, Lemelle I, Chalom EC, Sigal LH, Block A, Covucci A, Nys M, Martini A, Giannini EH. Abatacept improves health-related quality of life, pain, sleep quality, and daily participation in subjects with juvenile idiopathic arthritis. Arthritis Care Res (Hoboken). 2010; 62:1542-51. [PubMed: 20597110]

20. Cohen AB, Lee D, Long MD, Kappelman MD, Martin CF, Sandler RS, Lewis JD. Dietary Patterns and Self-Reported Associations of Diet with Symptoms of Inflammatory Bowel Disease. Dig Dis Sci. 2012

21. Long MD, Kappelman MD, Martin CF, Lewis JD, Mayer L, Kinneer PM, Sandler RS. Development of an internet-based cohort of patients with inflammatory bowel diseases (CCFA Partners): Methodology and initial results. Inflamm Bowel Dis. 2012; 18:2099-106. [PubMed: 22287300]

22. Buysse DJ, Yu L, Moul DE, Germain A, Stover A, Dodds NE, Johnston KL, Shablesky-Cade MA, Pilkonis PA. Development and validation of patient-reported outcome measures for sleep disturbance and sleep-related impairments. Sleep. 2010; 33:781-92. [PubMed: 20550019]

23. Yu L, Buysse DJ, Germain A, Moul DE, Stover A, Dodds NE, Johnston KL, Pilkonis PA. Development of short forms from the PROMIS sleep disturbance and Sleep-Related Impairment item banks. Behav Sleep Med. 2012; 10:6-24. [PubMed: 22250775]

24. Buysse DJ, Reynolds CF 3rd, Monk TH, Berman SR, Kupfer DJ. The Pittsburgh Sleep Quality Index: a new instrument for psychiatric practice and research. Psychiatry Res. 1989; 28:193-213. [PubMed: 2748771]

25. Bjorner JB, Chang CH, Thissen D, Reeve BB. Developing tailored instruments: item banking and computerized adaptive assessment. Qual Life Res. 2007; 16 (Suppl 1):95-108. [PubMed: 17530450]

26. Silverberg MS, Satsangi J, Ahmad T, Arnott ID, Bernstein CN, Brant SR, Caprilli R, Colombel JF, Gasche C, Geboes K, Jewell DP, Karban A, Loftus EV Jr, Pena AS, Riddell RH, Sachar DB, Schreiber S, Steinhart AH, Targan SR, Vermeire S, Warren BF. Toward an integrated clinical, molecular and serological classification of inflammatory bowel disease: Report of a Working Party of the 2005 Montreal World Congress of Gastroenterology. Can J Gastroenterol. 2005; 19 (Suppl A):5-36. [PubMed: 16151544]

27. Best WR, Becktel JM, Singleton JW, Kern F Jr. Development of a Crohn's disease activity index. National Cooperative Crohn's Disease Study. Gastroenterology. 1976; 70:439-44. [PubMed: 1248701]

28. Walmsley RS, Ayres RC, Pounder RE, Allan RN. A simple clinical colitis activity index. Gut. 1998; 43:29-32. [PubMed: 9771402]

29. Morisky DE, Ang A, Krousel-Wood M, Ward HJ. Predictive validity of a medication adherence measure in an outpatient setting. J Clin Hypertens (Greenwich). 2008; 10:348-54. [PubMed: 18453793]

30. Brass SD, Duquette P, Proulx-Therrien J, Auerbach S. Sleep disorders in patients with multiple sclerosis. Sleep Med Rev. 2010; 14:121-9. [PubMed: 19879170]

31. Chandrasekhara PK, Jayachandran NV, Rajasekhar L, Thomas J, Narsimulu G. The prevalence and associations of sleep disturbances in patients with systemic lupus erythematosus. Mod Rheumatol. 2009; 19:407-15. [PubMed: 19521744]

32. Fragiadaki K, Tektonidou MG, Konsta M, Chrousos GP, Sfikakis PP. Sleep disturbances and interleukin 6 receptor inhibition in rheumatoid arthritis. J Rheumatol. 2012; 39:60-2. [PubMed: 22133618]

33. Graff LA, Vincent N, Walker JR, Clara I, Carr R, Ediger J, Miller N, Rogala L, Rawsthorne P, Lix $\mathrm{L}$, Bernstein $\mathrm{CN}$. A population-based study of fatigue and sleep difficulties in inflammatory bowel disease. Inflamm Bowel Dis. 2011; 17:1882-9. [PubMed: 21830266]

34. Hall MH, Okun ML, Sowers M, Matthews KA, Kravitz HM, Hardin K, Buysse DJ, Bromberger JT, Owens JF, Karpov I, Sanders MH. Sleep is associated with the metabolic syndrome in a multiethnic cohort of midlife women: the SWAN Sleep Study. Sleep. 2012; 35:783-90. [PubMed: 22654197] 
35. Irwin MR, Olmstead R, Carrillo C, Sadeghi N, Fitzgerald JD, Ranganath VK, Nicassio PM. Sleep loss exacerbates fatigue, depression, and pain in rheumatoid arthritis. Sleep. 2012; 35:537-43. [PubMed: 22467992]

36. Luyster FS, Chasens ER, Wasko MC, Dunbar-Jacob J. Sleep quality and functional disability in patients with rheumatoid arthritis. J Clin Sleep Med. 2011; 7:49-55. [PubMed: 21344040]

37. Simpson N, Dinges DF. Sleep and inflammation. Nutr Rev. 2007; 65:S244-52. [PubMed: 18240557]

38. Graff LA, Walker JR, Bernstein CN. Depression and anxiety in inflammatory bowel disease: a review of comorbidity and management. Inflamm Bowel Dis. 2009; 15:1105-18. [PubMed: 19161177]

39. Shoham S, Davenne D, Cady AB, Dinarello CA, Krueger JM. Recombinant tumor necrosis factor and interleukin 1 enhance slow-wave sleep. Am J Physiol. 1987; 253:R142-9. [PubMed: 3496800]

40. Rohleder N, Aringer M, Boentert M. Role of interleukin-6 in stress, sleep, and fatigue. Ann N Y Acad Sci. 2012; 1261:88-96. [PubMed: 22823398]

41. Lange T, Dimitrov S, Born J. Effects of sleep and circadian rhythm on the human immune system. Ann N Y Acad Sci. 2010; 1193:48-59. [PubMed: 20398008] 


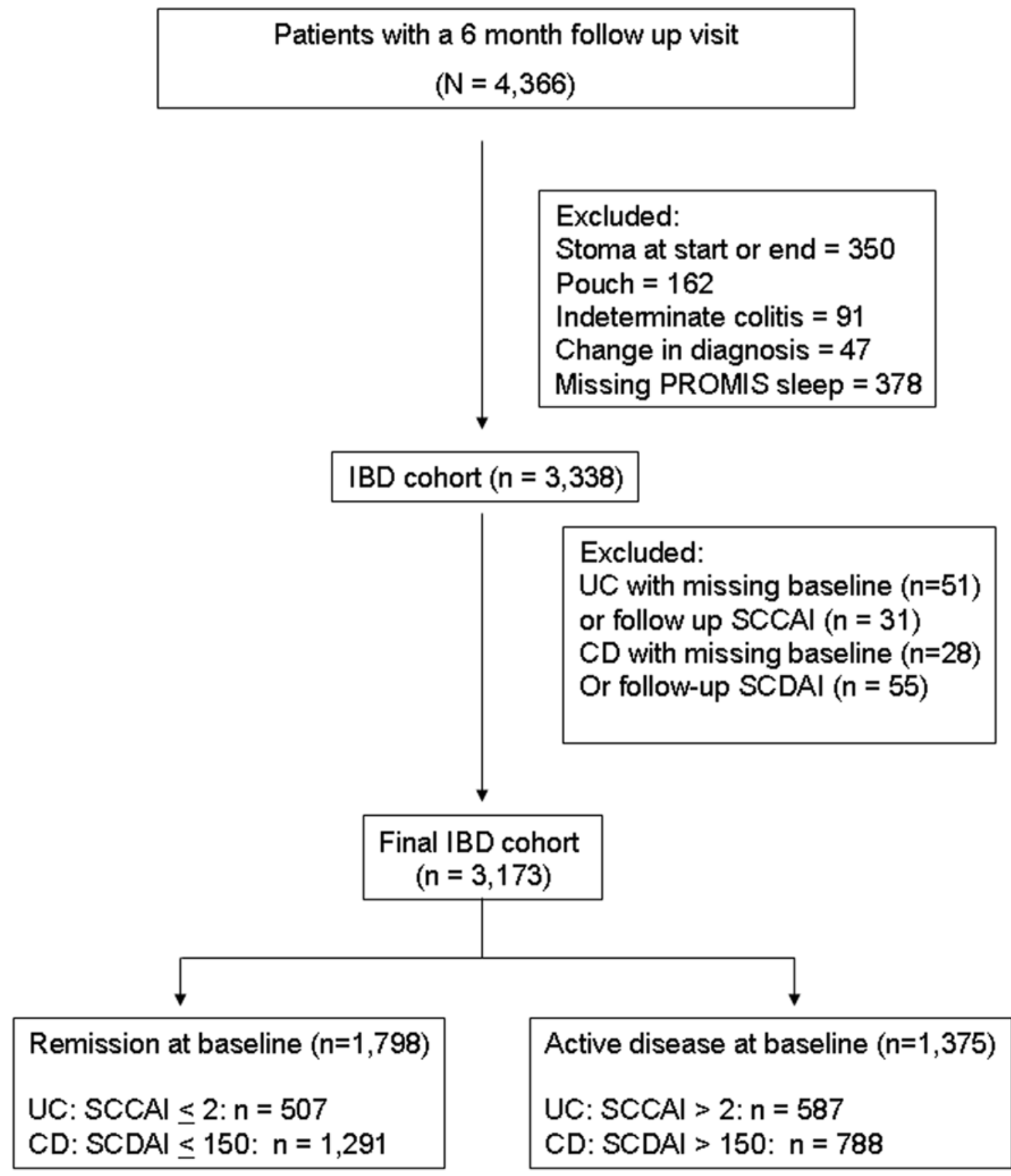

Figure 1. Flow chart establishing study cohort

PROMIS - NIH Patient Reported Outcomes Measurement Information Systems IBD - Inflammatory bowel disease

SCDAI - short Crohn's disease activity index, SCCAI - simple clinical colitis activity index 
Table 1

Baseline characteristics of the study cohort

\begin{tabular}{|c|c|c|c|}
\hline & No sleep disturbance $(\mathrm{n}=1,267) \%$ & Disturbed sleep $(\mathrm{n}=1,906) \%$ & p-value \\
\hline Median age in years (IQR) & $43(31-57)$ & $45(32-56)$ & 0.90 \\
\hline Median age at diagnosis (IQR) & $26(20-39)$ & $27(20-39)$ & 0.94 \\
\hline Female & 70 & 75 & 0.005 \\
\hline IBD type & & & 0.003 \\
\hline Crohn's disease & 62 & 68 & \\
\hline Ulcerative colitis & 38 & 32 & \\
\hline Smoking status & & & $<0.001$ \\
\hline Never & 68 & 61 & \\
\hline Past & 28 & 32 & \\
\hline Current & 4 & 7 & \\
\hline Family history of IBD & 24 & 22 & 0.06 \\
\hline Depressive symptoms $t$ & 33 & 63 & $<0.001$ \\
\hline \multicolumn{4}{|l|}{ Current medication use } \\
\hline Steroids & 10 & 17 & $<0.001$ \\
\hline 5-aminosalicylates & 52 & 49 & 0.10 \\
\hline Immunomodulators & 32 & 30 & 0.41 \\
\hline Anti-TNF biologics & 31 & 34 & 0.04 \\
\hline Narcotics & 4 & 11 & $<0.001$ \\
\hline Prior IBD surgery & 30 & 35 & 0.005 \\
\hline Prior hospitalization & 59 & 63 & 0.01 \\
\hline Crohn's Phenotype & & & 0.05 \\
\hline Inflammatory & 42 & 37 & \\
\hline Stricturing & 38 & 39 & \\
\hline Penetrating & 19 & 23 & \\
\hline Crohn's Location & & & 0.004 \\
\hline Ileal & 34 & 30 & \\
\hline Colonic & 17 & 13 & \\
\hline Ileocolonic & 47 & 56 & \\
\hline Upper GI only & 2 & 1 & \\
\hline Perianal Crohn's & 26 & 30 & 0.09 \\
\hline UC Extent & & & 0.65 \\
\hline Proctitis & 5 & 5 & \\
\hline Left-sided colitis & 43 & 42 & \\
\hline Pancolitis & 37 & 40 & \\
\hline Unavailable & 15 & 13 & \\
\hline Active disease ${ }^{\dagger}$ & 26 & 55 & $<0.001$ \\
\hline
\end{tabular}

Clin Gastroenterol Hepatol. Author manuscript; available in PMC 2014 August 01. 
${ }^{\dagger}$ Active disease was defined as $\mathrm{SCCAI}>2$ for patients with $\mathrm{UC}$ and a SCDAI > 150 for patients with $\mathrm{CD}$ 
Table 2

Predictors of disturbed sleep// at baseline in the full cohort $(n=3,173)$

\begin{tabular}{|c|c|c|}
\hline Parameter & Odds Ratio & $95 \%$ confidence interval \\
\hline \multicolumn{3}{|l|}{ Sex } \\
\hline Male & Reference & \\
\hline Female & 1.18 & $0.99-1.41$ \\
\hline \multicolumn{3}{|l|}{ IBD type } \\
\hline Crohn's disease & Reference & \\
\hline Ulcerative colitis & 0.74 & $0.61-0.90$ \\
\hline \multicolumn{3}{|l|}{ Smoking status } \\
\hline Never & Reference & \\
\hline Past & 1.28 & $1.09-1.50$ \\
\hline Current & 2.17 & $1.55-3.03$ \\
\hline \multicolumn{3}{|l|}{ Steroid use } \\
\hline No & Reference & \\
\hline Yes & 1.33 & $1.04-1.70$ \\
\hline \multicolumn{3}{|l|}{ Anti-TNF use } \\
\hline No & Reference & \\
\hline Yes & 1.03 & $0.87-1.23$ \\
\hline \multicolumn{3}{|l|}{ Narcotics } \\
\hline No & Reference & \\
\hline Yes & 1.65 & $1.17-2.35$ \\
\hline \multicolumn{3}{|c|}{ Prior IBD hospitalization } \\
\hline No & Reference & \\
\hline Yes & 1.06 & $0.88-1.28$ \\
\hline \multicolumn{3}{|l|}{ Prior IBD surgery } \\
\hline No & Reference & \\
\hline Yes & 0.87 & $0.71-1.07$ \\
\hline \multicolumn{3}{|l|}{ Active disease ${ }^{\dagger}$} \\
\hline No & Reference & \\
\hline Yes & 2.61 & $2.19-3.11$ \\
\hline \multicolumn{3}{|c|}{ Depressive symptoms ${ }^{t}$} \\
\hline No & Reference & \\
\hline Yes & 2.75 & $2.34-3.23$ \\
\hline \multicolumn{3}{|c|}{ /Disturbed sleep was defined as having a PROMIS sleep T-score $>5$} \\
\hline
\end{tabular}


Table 3

Characteristics of the cohort of patients in remission at baseline, stratified by sleep disturbance/l

\begin{tabular}{|c|c|c|c|}
\hline & No sleep disturbance $(n=932) \%$ & Disturbed sleep $(n=857) \%$ & p-value \\
\hline Age & $45(16)$ & $45(15)$ & 0.67 \\
\hline Age at diagnosis & $30(14)$ & $30(13)$ & 0.80 \\
\hline Female & 69 & 74 & 0.04 \\
\hline IBD type & & & 0.001 \\
\hline $\mathrm{CD}$ & 68 & 75 & \\
\hline $\mathrm{UC}$ & 32 & 25 & \\
\hline Smoking status & & & 0.015 \\
\hline Never & 70 & 64 & \\
\hline Past & 26 & 31 & \\
\hline Current & 4 & 5 & \\
\hline Family history of IBD & 24 & 24 & 0.96 \\
\hline Depressive symptoms ${ }^{t}$ & 27 & 50 & $<0.001$ \\
\hline \multicolumn{4}{|l|}{ Current medication use } \\
\hline Steroids & 7 & 9 & 0.10 \\
\hline 5-aminosalicylates & 51 & 49 & 0.59 \\
\hline Immunomodulators & 32 & 30 & 0.27 \\
\hline Anti-TNF therapy & 32 & 33 & 0.64 \\
\hline Narcotics & 3 & 5 & 0.06 \\
\hline Prior IBD surgery & 68 & 63 & 0.06 \\
\hline Prior hospitalization & 40 & 38 & 0.34 \\
\hline Crohn's Phenotype & & & 0.11 \\
\hline Inflammatory & 42 & 41 & \\
\hline Stricturing & 39 & 36 & \\
\hline Penetrating & 19 & 24 & \\
\hline Crohn's Location & & & 0.16 \\
\hline Ileal & 36 & 34 & \\
\hline Colonic & 17 & 13 & \\
\hline Ileocolonic & 46 & 52 & \\
\hline Upper GI only & 1.6 & 1.4 & \\
\hline Perianal Crohn's & 26 & 28 & 0.61 \\
\hline UC Extent & & & 0.33 \\
\hline Proctitis & 5 & 4 & \\
\hline Left-sided colitis & 38 & 45 & \\
\hline Pancolitis & 40 & 38 & \\
\hline Unavailable & 16 & 12 & \\
\hline
\end{tabular}

IBD - Inflammatory bowel disease; CD - Crohn's disease; UC - ulcerative colitis; SD - standard deviation

"Disturbed sleep was defined as having a PROMIS sleep T-score > 50

${ }^{t}$ Depressive symptoms were defined as having a PROMIS depression T-score $>50$ 


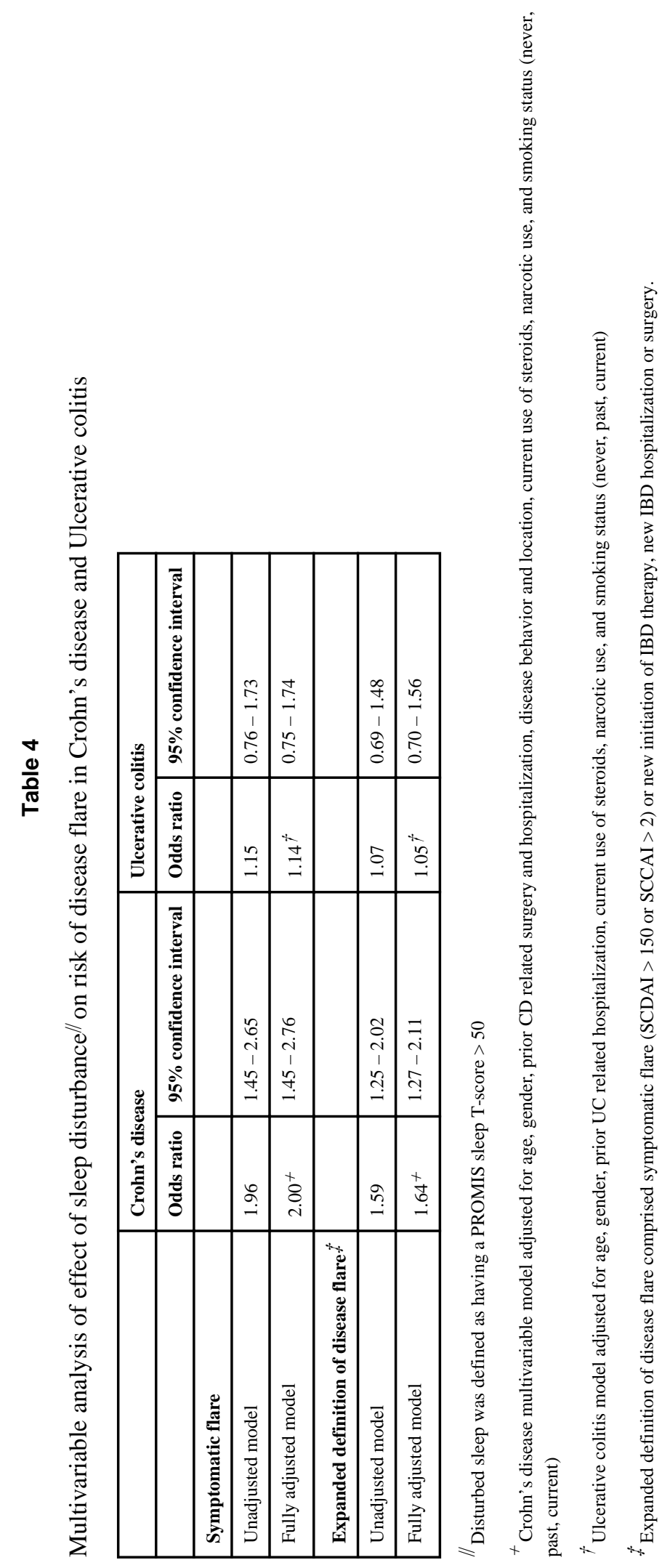

Clin Gastroenterol Hepatol. Author manuscript; available in PMC 2014 August 01. 


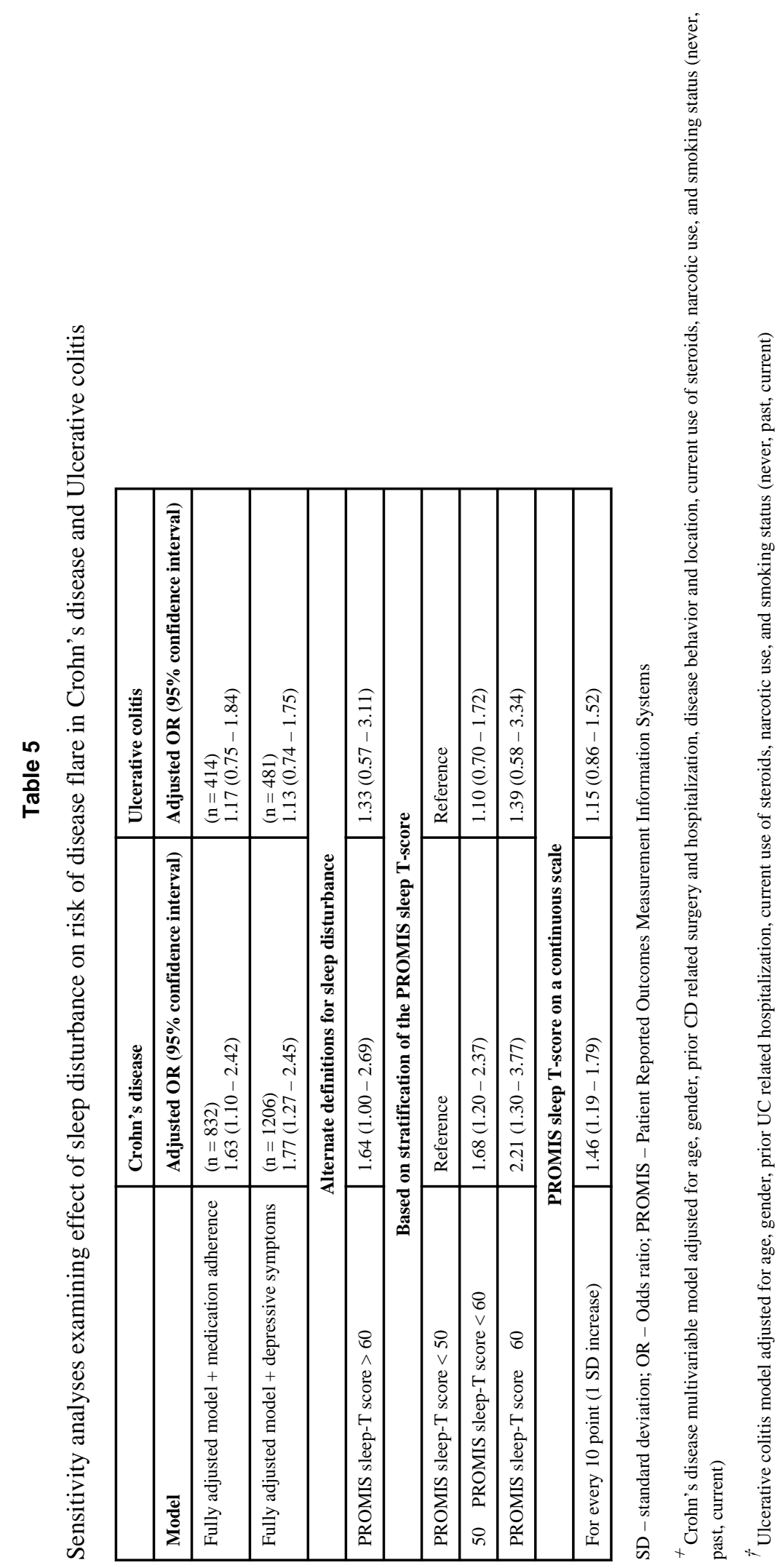

Clin Gastroenterol Hepatol. Author manuscript; available in PMC 2014 August 01. 